\title{
Peak Inspiratory Flow Rate
}

National Cancer Institute

\section{Source}

National Cancer Institute. Peak Inspiratory Flow Rate. NCI Thesaurus. Code C120939.

The fastest flow rate of gas noted during the inspiratory cycle. 